Saudi Journal of Oral and Dental Research

Abbreviated Key Title: Saudi J Oral Dent Res

ISSN 2518-1300 (Print) |ISSN 2518-1297 (Online)

Scholars Middle East Publishers, Dubai, United Arab Emirates

Journal homepage: https://saudijournals.com

\title{
The Effect of Third Molar on Orthodontic Treatment: A Systematic Review
}

Dr. Abdullah Ibrahim Alkharji*, Dr. AbdulMohsen Khaled Alanazi, Dr. Mohammed Abdullah Alharbi, Dr. Ghaida Ali Alsulaiman, Dr. Mohammed Mansour Alzehefi, Dr. Mohra Khaled Almuzaini, Dr. AbdulkarimAbdulaziz Alfadda, Dr. Ahmad Fathi Alomar, Dr. Laila Mohammed Alanazi, Dr. Fatima Sultana

Department of Dentistry, King Saudi University, Saudi Arabia

DOI: $\underline{10.36348 / \text { sjodr.2020.v05i11.004 }}$

| Received: 07.11.2020 | Accepted: 18.11.2020 | Published: 20.11.2020

*Corresponding author: Dr. Abdullah Ibrahim Alkharji

\section{Abstract}

Third Molar is the most posterior tooth of the three molars in human dentition. Wisdom teeth eruption is variable and it occurs generally in later teens and early twenties. If not enough space is available then the wisdom teeth gets impacted against the other teeth and this impaction does not cause movement of other teeth, but causes dental caries if oral hygiene is not maintained. The impaction prediction is scientifically not proven yet and hence the dentists cannot predict that, one should extract or not extract the third molars. The main aim of this research was to review the literature related to the relationship between the third molar and the orthodontic treatment. The third molar extraction is not directly involved in the orthodontic treatment but it can influence the treatment planning. A online base web search was made using various databases like Medline, Pubmed Central, Embase, Scopus, Google Scholar, Directory of Open Access Journals (DOAJ), and Cochrane electronic databases.The systematic review of literature is carried out in English language. The research was done in a time range of 6 months to study and review all the literature and prepare the manuscript. According to our reviewing of literature, we found that many investigators agree that the extraction of teeth during the orthodontic treatment has a positive effect on the eruption of the third molars. Majority of the authors also agreed that if any patient that had angulation of third molar had a good effect with the extraction therapy of orthodontics. It was reviewed that, if the extractions are indicated in future then the third molars are extracted before the adulthood, in order to avoid the inconvenience and the complications risk.

Keywords: Orthodontic treatment, third molars, wisdom teeth, systematic review, extraction therapy.

Copyright () 2020 The Author(s): This is an open-access article distributed under the terms of the Creative Commons Attribution 4.0 International License (CC BY-NC 4.0) which permits unrestricted use, distribution, and reproduction in any medium for non-commercial use provided the original author and source are credited.

\section{INTRODUCTION}

The role of the third molar is very controversial in the orthodontics as it may develop malocclusion or relapse after the orthodontic treatment especially in case of anterior dental arch. Although several studies have been available online, but still this issue is un-resolved. The literature showed studies that hypothesized that eruption of the third molars can cause misplacement or rotation of the tooth significantly in case of canines and incisors [1].

The surgery of the Third molars is one of the common oral surgeries known. In a study it was reported that in the United States of America, about ten million teeth are extracted every year [2]. The prevalent risk factors that cause the extraction of the third molars may be pericoronitis, caries, odontogenic cysts, periodontal defects and crowding of teeth. About 59\% of the patients are advised to remove their third molars by the Dentist. The impaction prediction is scientifically not proven yet and hence the dentists cannot predict that, one should extract or not extract the third molars.

The systemic review of the literature has shown that the oral surgeons and orthodontist recommends extracting the third molar to prevent crowding of teeth on their eruption [3]. The third molars can also replace the pre-molars and the first and second molars if they were previously extracted [4]. The third molars can help us derive the stem cells from a healthy patient and can be used for regenerative medicine [5].

Before starting the orthodontic therapy, the extraction of the third molar is decided to plan the treatment. The orthodontic treatment can be planned by having a detailed anamnesis, clinical examining patient, radio-graph studying, and model analysis. The best optimal age for the extraction of the third molars is between 17 to 20 years. Few of the authors suggest a problem to arise with the third molars in the orthodontic treatment [6]. 
Haider et al. and Shalhoub et al. reported in their studies about 30 years ago that in Saudi Arabia, the impaction of third molar is more in the males when cpompared to females [7]. The patterns and prevalence of third molar impaction was studied in different regions of Saudi Arabia by El- Khateeb et al. [8]. Alfadil et al. studied the third molar impaction pattern in Riyadh, Saudi Arabia and also about the possible reasons of extractions [9]. A Radiographic retrospective study was carried out to understand the prevalence of impacted third molars among the Saudi patients by Alamri et al. [10].

\section{AIM \& OBJECTIVES}

The main aim of this research was to review the literature related to the relationship between the third molar and the orthodontic treatment. This can be attained by:

- Carrying out an online search of databases for the literature related to third molar and orthodontic treatment.

- Systematically reviewing the literature available on Pubmed Central, Medline, Scopus, Embase, Google Scholar, etc.

- Identifying the complications related to the orthodontic treatment and the extracted third molars.

- Determining the effect of extraction of third molars and the impaction of teeth.

\section{Third molar (wisdom tooth)}

The Third molar is called as Wisdom tooth as it appears much later than the other teeth and most probably at an age where the person is wiser than as a child. It is the most posterior tooth of the three molars in human dentition. Most of the adults have 4 wisdom teeth, but it is possible to have none, less or more; the extra wisdom tooth is call supernumerary teeth. Wisdom teeth eruption is variable and it occurs generally in later teens and early twenties. If not enough space is available then the wisdom teeth gets impacted against the other teeth and this impaction does not cause movement of other teeth, but causes tooth decay if oral hygiene is not maintained.

The partially erupted wisdom teeth can cause inflammation and infection of the surrounding gums resulting in a condition called pericoronitis. If Pericoronitis occurs the wisdom teeth is often extracted. Wisdom tooth is often considered as the most commonly impacted teeth in the human beings. The lack of space in the eruption of the wisdom teeth often creates a risk for periodontal diseases and cavities which increases by age. The eruption of the third molar is known to cause dental problems since Millennium (back as far as Aristotle). In today's industrial era the problem becomes ten times more common due to the prevalence of processed and sugary foods.

\section{Third molar extraction (dento alveolar surgery)}

The oral and maxillofacial surgeons often extract the third molar by a surgical procedure. In order to minimise complications, a well-planned surgical approach is made. In Spite of the best efforts the complications are expected and hence it's significant to counsel the patient before the operation's potential risk. The extraction of the third molar causes the Sensory nerve injury; an incidence of $0.4 \%$ to $5 \%$ is noted in case of the nerve injury. The inferior alveolar nerve injury is more incident when compared to the lingual Nerve [11].

In the extraction of the third molar, the complications related to local anaesthesia also occurred probably due to direct needle trauma to the inferior alveolar Nerve. The infection of the third molar is very common before and after the surgery, due to the the removal of partial and full bony impaction. The infections can occur soon after the procedure or late and it can be found localised to the area of third molars or even spread to other facial spaces and can cause lifethreatening infections. Most of the infections of the third molar can be treated easily by using a wide range of Antibiotics.

One of the well-known complications of third molar extraction is the Dry socket or localised osteitis. The Other complications of the third molar extraction like the periodontal risks, displacement of a fragment of the bone into the Sinus, oral-antral communication, Tempo mandibular joint(TMJ) Pain, haemorrhage, dehiscense of the wound, fracture of the mandible, emphysema of the soft tissue [11].

\section{Third molar extraction and orthodontic treatment}

The third molar extraction is not directly involved in the orthodontic treatment but it can influence the treatment planning. Some common issues with the extraction of the third molars in relation to the orthodontic treatment are possible eruption of the third molars and impaction of the other teeth, and mandibular incisor relapse after the Orthodontic treatment.

The genetically determined dental factors effect the presence or absence of the third molars in the oral cavity of humans. Bowdler et al. reported that the eruption of the third molar is an important factor in the individual's growth pattern [12]. Begg et al. acknowledged in his research that the impaction of the third molars occurs due to lack of inter-proximal attrition in dentition of modern man when compared to the ancient skulls [13]. In a longitudinal cephalometric study, it was identified that two skeletal and two dental factors are linked with the impaction of the third molar [14]. Riketts et al. in his research concluded that the third molar have $50 \%$ chance of erupting with $50 \%$ of the Crown lying ahead of the external ridge, he also claimed that the direction of eruption of the tooth 
plays a significant role in the third molar impaction [15].

Kaplan et al. agree that patients with third molar's impacted shows a large angle of mandibular growth when compared to the patients with erupted third molars [16]. Richardson et al. studied 95 cases in his longitudinal study and suggested that the mandible with short length, narrow width and more acute angle is more prone in the third molar impaction [17]. Ades et al. studied 97 patients and concluded that there is no significant difference in mandibular growth between those who had impacted or fully erupted mandibular third molars [18]. Hasan studied 121 Saudi patients in his retrospective cephalometric study and acknowledged that third molar impaction is more likely to occur if there is an inadequate retro-molar space [19].

During the active growth of a person, the orthodontic treatment usually influences the development of dentition. According to the existing literature, the third molars are highly affected by the orthodontic treatment. Usually in case of the orthodontic treatment, the permanent pre-molars are removed depending on the treatment requirement. One of the first authors to suggest that the premolar extraction increases the probability of third molar eruption was Kaplan et al. in case of extraction therapy [16]. According to Kaplan et al if eruption doesn't occur in extraction cases, an insignificant resorption of the anterior border of ramus occurs and is responsible for the vertical growth type [16].

Rindler et al. studied and reported that the third molars replaced the second molars in about $77 \%$ of the cases; He did this by examining the data from the Lateral oblique radio-graphs of around 78 patients [20]. According to Williams et al. the change in the rate of third molar eruption after the premolar extraction was indifferent and had a crucial positive impact [21].

Richardson et al. reported that the third molars had a tendency to auto correct the bucco-lingual inclination adjacent to second molar extraction and also that if the development of the third molar is at the time of extraction then there are higher chances of their eruption [17].

Haavikko et al. analysed 110 longitudinal orthopantomogram of patients with mean age 13.5 years, concluded that the probability of the lower third molar eruption in 3 years and the extraction treatment accelerated eruption and do not promote it [22]. Cavanaugh et al. evaluated 25 patients and suggested third molars usually erupted in the space that is made by the removal of second molars [23]. Gooris et al. carried out a study on 95 patients in the age range 9 to 19 years and concluded that all those patients had erupted third molars that presented with a mesial inclination [24]. Moffitt et al. had examined 56 patients and concluded that the second molar extractions accelerated the eruption of the third molars [25].

Staggers et al. studied the radio-graphs of about 78 patients that were orthodontically treated and acknowledged that there is no considerable impact of the extractions of the molars on the angulation of third molars [26]. Elsey et al. studied the records of 30 patients with impacted lower third molars with a premolar extraction treatment and suggested that a positive influence of lower pre-molar extraction occurs on the position and inclination of impacted third molars [27].

Orton Gibbs et al. conducted a retrospective study of the records of 6 patients with mean age 13 years and concluded that both maxillary and mandibular third molars erupted in good or acceptable positions after the second molar extractions [28]. De-la-Rosa-Gay et al. Studied the panoramic radio-graphs of 48 patients in a retrospective study with mean age 14.8 years and concluded that the maxillary and mandibular third molar had erupted after the second molar extraction orthodontic treatment [29]. Kim et al. conducted a retrospective study on the records of 157 patients and suggested that clinical reduction in the compaction rate of maxillary and mandibular third molars is seen in patients with distractions when compared to the group of non-extraction [30].

Bayram et al. studied about the effect of first molar extractions during the orthodontic treatment on the third molar in about 41 patients with mean age 16.6 years and concluded that the frequency of the third molar impaction can be reduced by the extraction of the first molars [31]. Al Kuwari et al. performed a crosssectional study using the records of 40 patients available from the University clinic, and suggested that angulation of impacted third molars can be enhanced by the extraction of pre-molars during the orthodontic therapy [32].

Salehi et al. had assessed the clinical records of three group of patients and reported that there exist a crucial difference in the rate of eruption of the third molars in the extraction group, control group and nonextraction group, hence He indicated that the possibility of third molar eruption can be increased by the first premolar extractions [33]. Livas et al. Study the cephalometric radio-graphs of about 91 patient of mean age group 13.2 years and suggested that the extraction of first molars during the orthodontic treatment can significantly improve the position of the third molars [34].

Turkoz et al. Studied and compared two groups of 22 patients each with and without the first pre-molar extraction and found a significantly lower impaction rate of the third molars in the extraction grows [35]. Halicioglu et al. studied 294 
patient radio-graphs and conducted a retrospective study; the patients are in the age range 13 to 20 years and acknowledged that the development of third molars was significantly enhanced in the patients on the extraction sites [36].

Erdem et al. Studied the radio-graphs of about 27 patients and concluded that the impaction of the third molar is an unpredictable event and is increased in patients with vertical growth pattern on anterior rotation of the mandible [37]. Behbehani et al. conducted a retrospective study on the radio-graphs of 134 patients and indicated that the mandibular growth and eruption space are the most protective parameters of impaction [38].

\section{METHODOLOGY}

An online based, web search was made using various databases like Medline, Pubmed Central, Embase, Scopus, and Google Scholar, Directory of Open Access Journals (DOAJ), and Cochrane electronic databases. The systematic review of literature was carried out in English language. In the initial term of reviewing, no filters were applied to make sure all the studies are available for successive screening. Later on filters like only human studies, only English language studies were added. The literature review was conducted by studying about 46 articles related to the effect of the third molars on the orthodontic treatment and that meet all the inclusion criteria.

\section{Time Line of Study}

The research was done in a time range of 6 months to study and review all the literature and prepare the manuscript.

\section{DISCUSSION}

In orthodontics, the association between the teeth crowding and the wisdom teeth is contentious and mythical. The crowding of the lower incisors and the eruption of the third molars occur simultaneously, hence they are often linked. The extraction of the third molar can be a suitable preventive measure to reduce the chances of crowding. Bjork et al conducted a longitudinal study and reported that the late growth of the mandibular results in the up-righting of the incisors that causes crowding [39]. Most of the literature blames the eruption of third molar for the incisor crowding.

Niedzielska et al. reported that if sufficient space is available, the erupting third molar will not cause displacement of teeth, conversely if space is insufficient then the third molar eruption can cause crowding of the teeth [40]. While Sidlauskas et al and Trakiniene et al. evaluated 90 patients and reported that there is no evidence of teeth over-crowding due to the implication of third molars as an etiological factor [41]. Karasawa et al. studied 300 patients and concluded that there is no association between third molars presence or absence on the teeth overcrowding [42]. Harradine et al. reported that a minimal difference occurs between the third molar extractions versus third molar nonextraction during the orthodontic treatment [43]. In a study, that compared four groups, that erupted, nonextracted, extracted and congenitally absent reported that no difference was detected among the groups after three years of orthodontic treatment [44].

In the orthodontic treatment, the role of mandibular third molar in the lower anterior crowding of teeth have been studied and discussed very often. Bishara et al. acknowledged this controversial issue by stating that a relationship occurs between the third molar and the incisor alignment post treatment as they occur at the same time [45]. The NHS centre suggested that a weak association exists between the removal of third molar and the crowding. Mettes et al. reported that prophylactic removal of third molar in adolescents neither prevents nor reduces late incisor crowding [46].

According to our reviewing of literature, we found that many investigators agree that the extraction of teeth during the orthodontic treatment has a positive effect on the eruption of the third molars. Majority of the authors also agreed that if any patient that had angulation of third molar had a good effect with the extraction therapy of orthodontics. The other factors that effected the relation of the third molars and the orthodontic treatment are: types of initial malocclusions for the orthodontic therapy, age of the patient, development stage of the third molars during the time of extraction therapy, ethnological background of the patients, types of mechanics that were used for the orthodontic treatment. It was reviewed that, if the extractions are indicated in future then the third molars are extracted before the adulthood, in order to avoid the inconvenience and the complications risk. Further studies need to be carried out to get a clear picture about the decision to extract or not extract the third molars before the orthodontic treatment. The study need to be conducted in various regions of Saudi Arabia to get a clear idea about the effect of extraction of the third molar on the orthodontic treatment.

\section{CONCLUSION}

There is a lack of high quality clinical studies from scientific point of view about the relationship between the third molar extractions and the orthodontic treatment. Most of the studies carried out their research on a small sample of population. From the review of the literature, we are able to suggest that an association occurs between extraction of the third molars and the orthodontic therapy. More awareness needs to be created among the dentists, so that they can take a firm decision on choosing to extract or not to extract the third molars. 
Abdullah Ibrahim Alkharji et al; Saudi J Oral Dent Res, Nov, 2020; 5(11): 546-551

\section{ETHICAL CONSIDERATIONS \\ Compliance with ethical standards}

Ethical approval: This proposal does not contain any studies with human participants performed by any of the authors.

Conflict of interest: The authors do not have any commercial associations that might pose or create a conflict of interest with information presented in this communication. No intramural or extramural funding supported any aspect of this work.

\section{REFERENCES}

1. Costa, M. G. D., Pazzini, C. A., Pantuzo, M. C. G., Jorge, M. L. R., \& Marques, L. S. (2013). Is there justification for prophylactic extraction of third molars? A systematic review. Brazilian oral research, 27(2), 183-188.

2. Friedman, J. W. (2007). The prophylactic extraction of third molars: a public health hazard. American journal of public health, 97(9), 1554-1559.

3. Lindauer, S. J., Laskin, D. M., Tüfekçi, E., Taylor, R. S., Cushing, B. J., \& Best, A. M. (2007). Orthodontists' and surgeons' opinions on the role of third molars as a cause of dental crowding. American Journal of orthodontics and dentofacial orthopedics, 132(1), 43-48.

4. Lee, C. T., Zhang, S., Leung, Y. Y., Li, S. K., Tsang, C. C., \& Chu, C. H. (2015). Patients' satisfaction and prevalence of complications on surgical extraction of third molar. Patient preference and adherence, 9, 257.

5. Atari, M., Barajas, M., Hernández-Alfaro, F., Gil, C., Fabregat, M., Ferres Padro, E., ... \& Casals, N. (2011). Isolation of pluripotent stem cells from human third molar dental pulp. Histology and Histopathology: Cellular and Molecular Biology.

6. Sigron, G. R., Pourmand, P. P., Mache, B., Stadlinger, B., \& Locher, M. C. (2014). The most common complications after wisdom-tooth removal: part 1: a retrospective study of 1,199 cases in the mandible. Swiss dental journal, 124(10), 1042-1056.

7. Haidar, Z., \& Shalhoub, S. Y. (1986). The incidence of impacted wisdom teeth in a Saudi community. International journal of oral and maxillofacial surgery, 15(5), 569-571.

8. El-Khateeb, S. M., Arnout, E. A., \& Hifnawy, T. (2015). Radiographic assessment of impacted teeth and associated pathosis prevalence: Pattern of occurrence at different ages in Saudi male in Western Saudi Arabia. Saudi medical journal, 36(8), 973.

9. Alfadil, L., \& Almajed, E. (2020). Prevalence of impacted third molars and the reason for extraction in Saudi Arabia. The Saudi Dental Journal.

10. Alamri, A., Alshahrani, N., Al-Madani, A., Shahin, S., \& Nazir, M. (2020). Prevalence of Impacted
Teeth in Saudi Patients Attending Dental Clinics in the Eastern Province of Saudi Arabia: A Radiographic Retrospective Study. The Scientific World Journal, 2020.

11. Shahrokh, C., Bagheri, D.M.D., M.D. (2008). Dentoalveolar surgery, in Clinical Review of Oral and Maxillofacial Surgery.

12. Henry, C. B., \& Morant, G. M. (1936). A preliminary study of the eruption of the mandibular third molar tooth in man based on measurements obtained from radiographs, with special reference to the problem of predicting cases of ultimate impaction of the tooth. Biometrika, 28(3/4), 378427.

13. Begg, P.R. (1954). Stone Age man's dentition. Am J Orthod Dentofac Orthop, 40:298-312.

14. Almpani, K., Kolokitha, O.E. (2015). Role of third molars in orthodontics. World J Clin Cases, 3(2):132-140.

15. Ricketts, R.M., Turley, P., Chaconas, S., Schulhof, R. J. (1976). Third molar enucleation: diagnosis and technique. J Calif Dent Assoc, 4:52-57.

16. Kaplan, R. G. (1975). Some factors related to mandibular third molar impaction. Angle Orthod, 45:153-158.

17. Richardson, M.E. (1977). The etiology and prediction of mandibular third molar impaction. Angle Orthod, 47:165-172.

18. Ades, A. G., Joondeph, D. R., Little, R. M., \& Chapko, M. K. (1990). A long-term study of the relationship of third molars to changes in the mandibular dental arch. American Journal of Orthodontics and Dentofacial Orthopedics, 97(4), 323-335.

19. Hassan, A. H. (2011). Cephalometric characteristics of Class II division 1 malocclusion in a Saudi population living in the western region. The Saudi dental journal, 23(1), 23-27.

20. Rindler, A. (1977). Effects on lower third molars after extraction of second molars. The Angle Orthodontist, 47(1), 55.

21. Williams, R., \& Hosila, F. J. (1976). The effect of different extraction sites upon incisor retraction. American journal of orthodontics, 69(4), 388-410.

22. Haavikko, K., ALToNEN, M., \& MATTILA, K. (1978). Predicting angulational development and eruption of the lower third molar. The Angle Orthodontist, 48(1), 39-48.

23. Cavanaugh, J. J. (1985). Third molar changes following second molar extractions. The Angle Orthodontist, 55(1), 70-76.

24. Gooris, C. G., \& Joondeph, D. R. (1990). Eruption of mandibular third molars after second-molar extractions: a radiographic study. American Journal of Orthodontics and Dentofacial Orthopedics, 98(2), 161-167.

25. Moffitt, A. H. (1998). Eruption and function of maxillary third molars after extraction of second molars. The Angle Orthodontist, 68(2), 147-152. 
26. Staggers, J. A., Germane, N., \& Fortson, W. M. (1992). A comparison of the effects of first premolar extractions on third molar angulation. The Angle Orthodontist, 62(2), 135-138.

27. Elsey, M. J., \& Rock, W. P. (2000). Influence of orthodontic treatment on development of third molars. British journal of oral \& maxillofacial surgery, 4(38), 350-353.

28. Orton-Gibbs, S., Orton, S., \& Orton, H. (2001). Eruption of third permanent molars after the extraction of second permanent molars. Part 2: Functional occlusion and periodontal status. American Journal of Orthodontics and Dentofacial Orthopedics, 119(3), 239-244.

29. De-la-Rosa-Gay, C., Valmaseda-Castellón, E., \& Gay-Escoda, C. (2006). Spontaneous third-molar eruption after second-molar extraction in orthodontic patients. American journal of orthodontics and dentofacial orthopedics, 129(3), 337-344.

30. Kim, T. W., Årtun, J., Behbehani, F., \& Artese, F. (2003). Prevalence of third molar impaction in orthodontic patients treated nonextraction and with extraction of 4 premolars. American journal of orthodontics and dentofacial orthopedics, 123(2), 138-145.

31. Bayram, M., Özer, M., \& Arici, S. (2009). Effects of first molar extraction on third molar angulation and eruption space. Oral Surgery, Oral Medicine, Oral Pathology, Oral Radiology, and Endodontology, 107(2), e14-e20.

32. Al Kuwari, H. M., Talakey, A. A., Al-Sahli, R. M., \& Albadr, A. H. (2013). Influence of orthodontic treatment with first premolar extraction on the angulation of the mandibular third molar. Saudi Med J, 34(6), 639-43.

33. Salehi, P., \& Danaie, S. M. (2008). Lower third molar eruption following orthodontic treatment. EMHJ-Eastern Mediterranean Health Journal, 14 (6), 1452-1458, 2008.

34. Livas, C., Halazonetis, D. J., Booij, J. W., \& Katsaros, C. (2011). Extraction of maxillary first molars improves second and third molar inclinations in Class II Division 1 malocclusion. American journal of orthodontics and dentofacial orthopedics, 140(3), 377-382.

35. Türköz, Ç., \& Ulusoy, Ç. (2013). Effect of premolar extraction on mandibular third molar impaction in young adults. The Angle Orthodontist, 83(4), 572-577.
36. Halicioglu, K., Toptas, O., Akkas, I., \& Celikoglu, M. (2014). Permanent first molar extraction in adolescents and young adults and its effect on the development of third molar. Clinical oral investigations, 18(5), 1489-1494.

37. Erdem, D., Özdiler, E., Memikoglu, U. T., \& Baspinar, E. (1998). Third molar impaction in extraction cases treated with the Begg technique. The European Journal of Orthodontics, 20(3), 263-270.

38. Behbehani, F., Artun, J., \& Thalib, L. (2006). Prediction of mandibular third-molar impaction in adolescent orthodontic patients. American journal of orthodontics and dentofacial orthopedics, 130(1), 47-55.

39. Björk, A., Jensen, E., \& Palling, M. (1956). Mandibular growth and third molar impaction. Acta odontologica scandinávica, 14(3), 231-272.

40. Niedzielska, I. (2005). Third molar influence on dental arch crowding. The European Journal of Orthodontics, 27(5), 518-523.

41. Antanas, S., \& Giedre, T. (2006). Effect of the lower third molars on the lower dental arch crowding. Stomatologija, 8(3), 80-4.

42. Karasawa, L. H., Rossi, A. C., Groppo, F. C., Prado, F. B., \& Caria, P. H. F. (2013). Crosssectional study of correlation between mandibular incisor crowding and third molars in young Brazilians. Medicina oral, patologia oral y cirugía bucal, 18(3), e505.

43. Harradine, N. W., Pearson, M. H., \& Toth, B. (1998). The effect of extraction of third molars on late lower incisor crowding: a randomized controlled trial. British Journal of Orthodontics, 25(2), 117-122.

44. Van der Schoot, E. A. M., Kuitert, R. B., Van Ginkel, F. C., \& Prahl-Andersen, B. (1997). Clinical relevance of third permanent molars in relation to crowding after orthodontic treatment. Journal of dentistry, 25(2), 167-169.

45. Bishara, S. E. (1999). Third molars: a dilemma! Or is it?. American Journal of Orthodontics and Dentofacial Orthopedics, 115(6), 628-633.

46. Mettes, D. T., Nienhuijs, M. M., van der Sanden, W. J., Verdonschot, E. H., \& Plasschaert, A. (2005). Interventions for treating asymptomatic impacted wisdom teeth in adolescents and adults. Cochrane Database of Systematic Reviews, (2). 